\title{
BUSINESS
}

\section{A breed apart}

The US Food and Drug Administration may soon approve the use of cloned livestock for food. But
regulatory roadblocks aren't the only thing keeping clones off the menu, as Heidi Ledford reports.

W

atson 101 had already lived up to his name by the time he was 12 years old. He had the longest horns of any Texas Longhorn in the world - they spanned 101 inches $(260 \mathrm{~cm})$ from tip to tip, and were still growing. Watson could have earned thousands ofdollars as a sire, but had been castrated before breeders saw his potential. So Watson's owner, Marquess Arrow Ranch in Texas, decided to order some dones of its prized steer.

Elite breeders of extraordinary cattle are currently the main customers for a livestockdoning industry that has struggled to take off since Dolly the sheep, the world's first cloned mammal, was born in 1996. The companies that sprang up to sell the technology have been in limbo as regulators in key markets such as the United States and Japan considered the admissibility of cloned meat into the food supply. "We're chained," says Mal Brandon, chairman of Clone International, an animalcloning companybasedin Melbourne, Australia. "Everything's been stalled while we've been waiting for dearance by the US authorities."

The chains are now loosening somewhat. The Food and Drug Administration (FDA) confirmed last month that it will release a draft risk assessment on the matter by the end of the year. But don't expect to find cloned meat in your supermarket in the near future. "The cost of cloning and the lack of efficiency in the process will preclude us from eating it any time soon," says Joe Paschal,
"The levels of efficiency will keep the number of clones relatively small." - David Faber

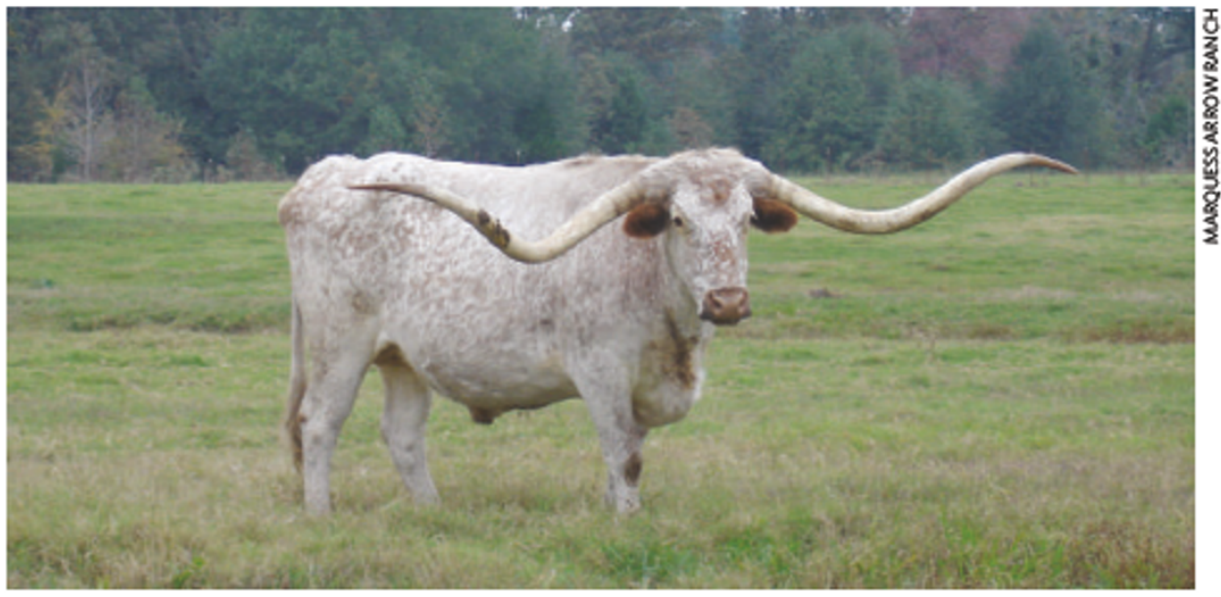

Immortal: Watson 101's genes can live on in his clones.

support of its principal shareholder, billionaire John Sperling. David Faber, president of Trans Ova Genetics, says that it recently attracted some venture capital, but notes that only about $5 \%$ of the company is focused on cloning farm animals. Cyagra declined to comment.

And ranchers haven't been stampeding to get hold of dones. Their primary concern is cost. ViaGen sells cloned pigs for around US $\$ 4,000$ each, for instance, whereas an uncloned sow might cost about $\$ 150$.

This means that the main target for the cloning companies is the top of the sophisticated breeding pyramid that produces today's farm animals. Last year, for example, farmers and ranchers in the United States spent A\&M University in Corpus Christi.

Business interest in livestock cloning is concentrated in the hands of three US companies - ViaGen of Austin, Texas; Trans Ova Genetics of Sioux Center, Iowa; and Cyagra of Elizabethtown, Pennsylvania. Clone International is also active, and there is significant research interest in cloning cattle in Japan.

All these firms have struggled to survive in the absence of regulatory approval. ${ }^{\alpha}$ This area requires quite a lot of cash," says Brandon, "and just to maintain it for research is not good business." Infigen, a Wisconsin-based company that was considered a major player, folded in 2004.

ViaGen president Mark Walton says that his company is not making money and has failed to attract venture capital, relying instead on the

\section{more than $\$ 225$ million on bull semen. Out-} standing sires can cost tens of thousands of dollars, says Paschal, with a few élite bulls worth more than half a million dollars. These prices make ViaGen's $\$ 15,000$ bull easier to accept.

Even in this niche, cloned animals will make up a tiny proportion of the breeding stock. According to Walton, it takes about 75,000 bulls to replenish the US dairy cattle herd, and 200,000 for the beef cattle herd. Last year, ViaGen produced just 50 cloned cattle.

Part of the challenge is technical. The efficiency of somatic cell nudear transfer - the technique used to produce Dolly — remains disappointingly low. Faber estimates that the proportion of bovine embryo transfers that result in a live birth at Trans Ova Genetics ranges from $8 \%$ to $25 \%$. And these numbers don't take account of the large proportion of embryos that die before being transferred to a surrogate mother. ${ }^{\alpha}$ The levels of efficiency will keep the number of clones relatively small,' says Faber. $\mathrm{He}$ nonetheless predicts that demand will increase as efficiencies improve and costs decrease.

\section{Export market}

Some companies are trying to build a niche by selling cloned cattle to poorer countries, such as China, to jump-start their cattle-breeding programmes. Xiangzhong Yang, director of the University of Connecticut's Center for Regenerative Biology and founder of Evergen Biotechnologies, claims that a cloned bull could achieve as much on Chinese farms in two years as a breeding programme taking seven years and costing up to a million dollars. And Clone International has already shipped four dones of New Zealand dairy bulls to China for use in research there. But Robert Blake, an animal scientist at Cornell University in Ithaca, New York, cautions that animals bred to succeed in one country may not fare as well when faced with foreign diseases and nutritional standards.

Alison Van Eenennaam, an animal biotechnology specialist at the University of California, Davis, says the hype around animal cloning has exaggerated its likely role in food production. "You hear a lot about it and you think there must be a zillion clones out there," says Van Eenennaam. "But the only place it's really getting used is the upper echelon of the breeding pyramid. 